\title{
The effects of a 39-kHz tone on passive-avoidance learning in preshocked rats: A failure to replicate*
}

\author{
CHRIS CUNNINGHAM $\uparrow$ and D. CHRIS ANDERSON \\ University of Notre Dame, Notre Dame, Ind. 46556
}

Preshock vs no-preshock was combined factorially with the presence of a $0-, 78-$, or $96-\mathrm{dB} 39.2-\mathrm{kHz}$ tone during punishment of the water-licking response of water-deprived rats. Preshock treatment reliably increased the latency to the first lick following punishment, but the ultrasonic tone failed to show any effect.

Two recent studies have indicated that an ultrasonic tone influences the behavior of rats when they are shocked, especially if they have had prior experience with unsignaled inescapable shock (preshock). Anderson, Murcurio, \& Mahoney (1970) found that a high-frequency tone $(39.2 \mathrm{kHz}, 78 \mathrm{~dB})$ eliminated the debilitating effect of preshock on footshock-elicited fighting behavior. Anderson, Cunningham, \& Simons (1970) reported that the same tone appeared to intensify the punishing effect of shock in a water-licking situation. In both studies, the tone's effect seemed to be restricted to the period during or just following the presentation of test shock.

The data reported by Anderson et al (1970a) suggested that the interactive effect of preshock and ultrasonic tone varied with the intensity of the tone, but this relation was obscured by the fact that the intensity of the tone was increased over successive test days within groups, thus not controlling for order effects or the cumulative effects of exposure to the tone and the punishment procedure. The present experiment was designed to replicate and extend the study of Anderson et al (1970a). Preshock vs no-preshock was combined factorially with the presence of a $0-, 78-$, or $96-\mathrm{dB}$ $39.2-\mathrm{kHz}$ tone during the punishment of a water-licking response.

\section{METHOD}

Sixty naive male albino rats, $90-100$ days old, were used. The drinking chamber was a standard Gerbrands operant-conditioning box (Model 4C), housed in a ventilated refrigerator shell. A bent stainless steel drinking tube mounted in a rubber washer was inserted through one of the aluminum ends of the chamber and was connected to one electrode of a Lehigh Valley drinkometer (Model 1520). A Plexiglas partition shielded all but the rat's mouth and tongue from the tip of the drinking tube. The grid floor constituted the other electrode of the drinkometer.

*This research was supported in part by United States Public Health Service Grant 14436-02 from the National Institute of Mental Health to D. Chris Anderson. The authors wish to thank James Rollins, John Fossum, and Katie Sudro for assistance in handling and running these animals.

†The first author is now at the Department of Medical Psychology, University of Oregon Medical School, Portland,
Oreg.
The transmitting and receiving transducers of an Alton ultrasonic motion detector (Model 5) were mounted $5 \mathrm{~cm}$ apart at the center of the Plexiglas lid of the chamber. The audio output of the device was approximately sinusoidal, with a frequency of $39.2 \mathrm{kHz}$, and a nominal sound pressure level adjustable to either 78 or $96 \mathrm{~dB}$ (see Anderson et al, 1970b, for calibration details).

A grid-floored box $(17.8 \mathrm{~cm}$ wide $\times 25.4 \mathrm{~cm}$ long $\mathrm{x} 20.4 \mathrm{~cm}$ high, inside) with stainless steel walls was used as the preshock chamber. The preshock source was a dc constant current device set at $1.25 \mathrm{~mA}$. The shock was scrambled, and its duration was timed with a stopwatch. The punishment shock source was the output of a transformer set at $70-\mathrm{V}$ ac in series with a $22-\mathrm{kilohm}$ resistor.

The study was run in two identical replications. Several days following reception from the supplier, the rats were placed on a 23-h, 50-min water-deprivation schedule (Day 1). On Days 3 and 4 , all rats were given daily water ration in the operant chamber and number of licks were recorded. Six groups then were formed, equated on the basis of the number of licks for these 2 days (5 rats/group per replication). The three preshock groups were then given 5 consecutive days of continuous unsignaled inescapable shock ( $3 \mathrm{~min} / \mathrm{day})$ in the preshock chamber. The remaining groups were treated identically, but were not shocked.

A 7-day rest period followed preshock treatment. In an attempt to extinguish any fear that might have generalized from the preshock chamber to the operant chamber, groups of three rats each were placed together in the operant chamber (with drinking tube removed) for a $30-\mathrm{min}$ session on Day 17 . On Day 18 , each rat was returned individually to the chamber and allowed to drink for $10 \mathrm{~min}$. On each of Days 18 and 19 , rats were tested during the drinking session. At the end of the first 100 licks, a 1-sec shock was made available at the drinking tube and was delivered for the next lick (the drinkometer was switched out for this 1 -sec period). Shock offset initiated an elapsed timer which recorded number of seconds to the first lick following punishment. An additional 130 licks initiated the second trial. This procedure continued until a total of five test trials had been completed. If the animal did not lick within 5 min following any $1-\mathrm{sec}$ punishment, it was returned to its home cage, and scores of $300 \mathrm{sec}$ were recorded for the remaining trials on that day.

\section{RESULTS AND DISCUSSION}

To reduce heterogeneity and skewness, latency scores to first lick following each shock were converted to logarithms [i.e., $\log ($ score +1$)$ ]. Since the preshock animals generally took longer to initiate licking at the beginning of the first test session, this measure, i.e., latency to first lick following placement in the test chamber, was used as the concomitant (uncontrolled) variable in a two-way factorial analysis of covariance involving preshock vs no-preshock and the three intensities of tone. (The days effect was not reliable and did not interact with any other variable, thus justifying collapse of the data over this dimension.) Preshock was reliably effective in increasing the "corrected" latencies to first lick following punishment $(\mathrm{F}=38.2, \mathrm{df}=1 / 53$, $\mathrm{p}<.01)$, but the ultrasonic tone failed to show any effects. 
The results of this experiment support the previous finding that preshocked rats take longer to resume water licking following punishment than do nonpreshocked controls. However. these data do not indicate any effect of the ultrasonic tone. and thus fail to replicate the results of Anderson et al (1970a). Aside from minor procedural changes. there is no apparent reason for this failure.

Although one interpretation of the present experiment might be simply that the ultrasonic tone has no effect in the passive-avoidance water-licking situation. this does not necessarily preclude either the possibility that the rat can hear the tone or that in a different situation. the tone may even be aversive ( $\mathrm{cf}$. Anderson et al. 1970b: (unningham ${ }^{1}$ ).

Indeed. to evaluate whether or not the $39-\mathrm{kHz}$ tone is audible to the rat. four 200-day-old naive rats were water deprived for $23 \mathrm{~h}$ and $50 \mathrm{~min}$ on each of 2 days. and then given their daily $10 \mathrm{~min}$ of water in the licking chamber. Total number of licks were recorded each day. On days when licking did not take place in the chamber. each $\mathrm{S}$ received his daily water as usual in his home cage.

On each of the next 2 days, two of the four Ss received 10 forward fear conditioning trials in the chamber similar to the licking chamber, but without the licking tube present. A forward conditioning trial consisted of a $30-\mathrm{sec} 39-\mathrm{kHz}$ tone $(78 \mathrm{~dB})$ overlapping and coterminating with a $2-\sec$ shock $(120 \mathrm{~V} \mathrm{ac})$. ITI was $60 \mathrm{sec}( \pm 2 \mathrm{sec})$. The remaining two $\mathrm{Ss}$ received similar treatment except that a random conditioning procedure was employed. Each $\mathrm{S}$ received a total of 20 trials.

The day following conditioning, all rats were returned to the licking chamber where they received their daily ration of water as before. On the following day, each again was returned to the licking chamber. After an initial 100 licks. a 30 -sec pretest period was initiated during which the total number of licks was recorded. Following this 30 -sec interval. a 30 -sec presentation of the CS took place. also during which the total number of responses was recorded. Approximately 100 licks later. the procedure was repeated until each $S$ received a total of five test presentations of the CS.

Collapsed over the five test presentations. the mean suppression ratio (Annau \& Kamin. 1961) for the forward conditioned group was .0867 and. for the random group. was $.3714(\mathrm{~F}=17.43 \mathrm{df}=1 / 2$. $\mathrm{p}<.053)$. Even more convincing data than these also have been collected and liave been submitted by the first author under a separate heading (Cunningham ${ }^{1}$ ). Until the full implications of the possible associative and/or motivational effects of ultrasonic stimuli become clear. it is recommended that Es who intend to use the ultrasonic motion-detecting device be aware of the fact that the rat can probably hear the high-frequency tone and that the tone may interact with treatment variables to affect the behavior under observation.

\section{REFERENCES}

Anderson, D. C., Cunningham, C., \& Simons, R. Intensification of passive-avoidance learning as a function of preshock and a $39 \mathrm{kHz}$ tone. Proceedings, 78 th Annual Convention, APA. $1970 \mathrm{a}, 247-248$.

Anderson, D. C., Murcurio, J., \& Mahoney, P. Inhibition of preshick-produced reflexive fighting by a $39 \mathrm{kHz}$ tone. Physiology \& Behavior, 1970b, 5, 577-581.

Annau, Z., \& Kamin, L. F. The conditioned emotional response as a function of the intensity of the US. Journal of Comparative \& Physiological Psychology, 1961, 54, 428-432.

\section{NOTE}

1. Cunningham, C. The ultrasonic motion detector as CS in the CER paradigm. In preparation.

(Received for publication November 5, 1973.) 